\title{
Impact of Risk Diversification in Industrial Investment by applying Topsis Method
}

\author{
C Vilvijayan*
}

\begin{abstract}
The major issues pertaining to the different projects is frequent day is mainly due to the delay in their completion. The most important reason is existence of risk and internal and external uncertainties. To solve this problem a program is needed to manage the risks and uncertainties and reduce their impacts on the objectives of the project. In this paper, in order to quantitatively analyze the risks in industrial investment project, using database supported by Topsis algorithm is suggested. By using Visual Basic software, a program is designed to identify the project risks.
\end{abstract}

Keywords: Risk management, Risk analysis, Database

\section{Introduction}

One of the important factors in investment is the uncertainty about the efficiency of the project of investment. This uncertainty is because of the different risks, which are in the project. Risk is an unavoidable factor. (Aladpoosh, 2002) In each organization all the activities are involved with risks. The traditional study has a negative view to the risk and considers the risk by the special phrases like: failure, danger and undesirable result. On the

* Asst Professor of Commerce, Commerce Wing, Directorate of Distance Education (DDE), Annamalai University, Tamil Nadu, India; vijaycr2006@gmail.com 
opposite site, in modern view, risk is shown as a negative factor and as a positive factor. (Gharachorlu,2006)The" positive risk" or chance means uncertainty that have a good result. It must be mentioned that both types of risks (positive and negative) need to be managed. Risk managing is a problem that is faced by people every day in every decision making. For example, bypassing the street. But risk management that we use in our daily life usually is natural and it is based on our experiments. Risk management gives this possibility to organizations to determine the level of risks. In this case, they will have the highest profit and the lowest loss. (Jaafari, 2001) Updating the risk information plays an important role in decision-making efficiency. Risk management in industrial investment projects is a process that studies and identifies risks by two aspects of threatening sources and after that it studies the performance probability. Then by choosing control procedures, studies the risk adjustment and increases the safety and possibility of project plan. (Hatefi, 2008) In this way, the probability of risks will be minimized.

\section{Literature review}

The studies about governmental risk management are started in 1950, and psychological risk is started in 1960.(Chapman, 2008)In the decades after1960 in database of the human error rate was emphasized. (Eloranta, 2007)Risk management as one of the new branches of management for the first time was published by Robert Mehr and BobHedges(1963) in a book by the title of "risk management in commercial institutes ".Risk analysis for the first time was defined by Research Committee of the National Research Council (1983). In this definition, 3 main steps of risk analyzing were mentioned: evaluation, management, risk transfer. In a research, done by Kliem and Ludin 1995), four steps (1, definition 2, analyzing 3, control 4, and report) were mentioned. David Vose (2000) determined the general law about the risk analyzing models by using simulation: each repetition in one risk analyzing model should be like a scenario that physically happens.

In Iran Ayyoob Mohamadi (2006) studied the risks in structure projects in industry. In this case, Hierarchical Structure of Risk and 
Uncertainty (HSRU) and also time evaluation process for organizing and structuring the risks and the uncertainties in structure projects in petrochemical industry were used. So that for increasing the accuracy of output evaluation of cause and effect will be separated. For this purpose the process of time evaluation as a measuring tool of output can be used. In this paper risk management is defined as a solution. Zhuan Nahid (2008)in a research by the title of "using risk in security of systems of information technology(IT),studies the threatening risks in the organization's informational systems and the necessity of their controls. In this research, the SDLC method or life cycle of system development for studying the risk adjustment process, which consists of risk adjustment option. Risk controlling methods. Classified methods of control, profit, loss and the acceptable level of risk analysis is studied. This method has 5 phases: 1 , the fist phase 2, the development phase 3, the performance phase 4 , the keeping phase 5, the disposal phase. Neda Mohammad Hassan (2006)in a research by the title of "Crisis management and its effect on the urban gas facilities and its solution" studied the urban gas supply facilities and damages in the case of earthquake and gave solutions to create the informational system of management between multiple disaster management committees. Hatefi(2008) in his PhD thesis by the title of Integrated Model Development Project Risk. Studied the designing of the integrated model for project risk response planning by the title of P2RP. In this model three main phases, risk definition, risk analysis, and risk response were studied. Also it was mentioned that by respecting to the two other phases, process programming and response performance, with monitoring and controlling the risks, this model can be used in form of risk management process. The purpose of this research is to use this model in the body of base model of subsystem as Decision Support System (DSS).

\section{Risk analysis process}

Each risk has cause and effect. If you use the data to solve the problems and give the solutions and make a decision in fact you analyze risks. Hillson, David (2002) By risk and methods of risk evaluation analysis process the analyzer can make a good decision 
.In this process the risk will be divided to its components. So risk analyzing is more than a definition. (Aaby, 2006).The most popular definition of the risk management defines 3 processes for it: (Yang and Qiu, 2005)

1-risk evaluation, which answers to these questions: what is the effect of the risk? What is the factor of the risk?

2-risk management that answers to this question: what can we do, if the risk happens?

3-risk transfer, that answers to these questions: how can be the risk defined? Who can make the decision about the risk?

Thus, risk analyze has two main goal. (Hatefi, 2008)The first one is that the risk analyze shows the relative important of the defined risks and makes it possible to classify the risks according to their priority and the effects on the operational and financial structure of the organizations. Second, it shows the necessary information for determining the suitable methods to deal with the risk.

\section{The structure of suggested data bank}

Because of the dynamism of the industrial investment risks, it is so important to keep the data updated. So, using data bank for structuring the information is useful. One of the important stages in analyzing is bringing up and registering the information. The future suggestions and decisions are based on this information that is collected in this stage. (Kerzner, 2001) if the information is not available due to the time limitation, the decision will be based on speculation and it will not have any good results. In this paper a method is suggested to utilizes database as a previous information source and experiments of previous projects and a place for registering the information, obtained during the analysis of new industrial risk project. In general structure of the suggested model, it was estimated that this database is created for the first time.

Analysis and comparison with the available cases were done and the information about the new risk for the future reference will be saved. This system has two main parts: data storage centre and executive division. The quality of information determines the 
quality of risk analysis and data bank is a place for collecting the information so the main emphasis is on the transparency of process inputs. (Santos and Cabral, 2005).The information of this databank is divided in two groups: information of the project of investment and database. The information about each project is studied and after the completion of project, some parts of the results are going to be transferred to the data base.

In database, besides this information some information such as data of the other banks, standards of industrial areas and other general information will be saved. The suggested database is something more than a place for saving the information. It can use a series of data in order to collect special data, so it has a form of knowledge base that by using that in future plans it will be developed. By increasing the information in this database it is possible to perform statistical analysis to check validity of data. In figure 1 the general structure of the suggested database is shown.

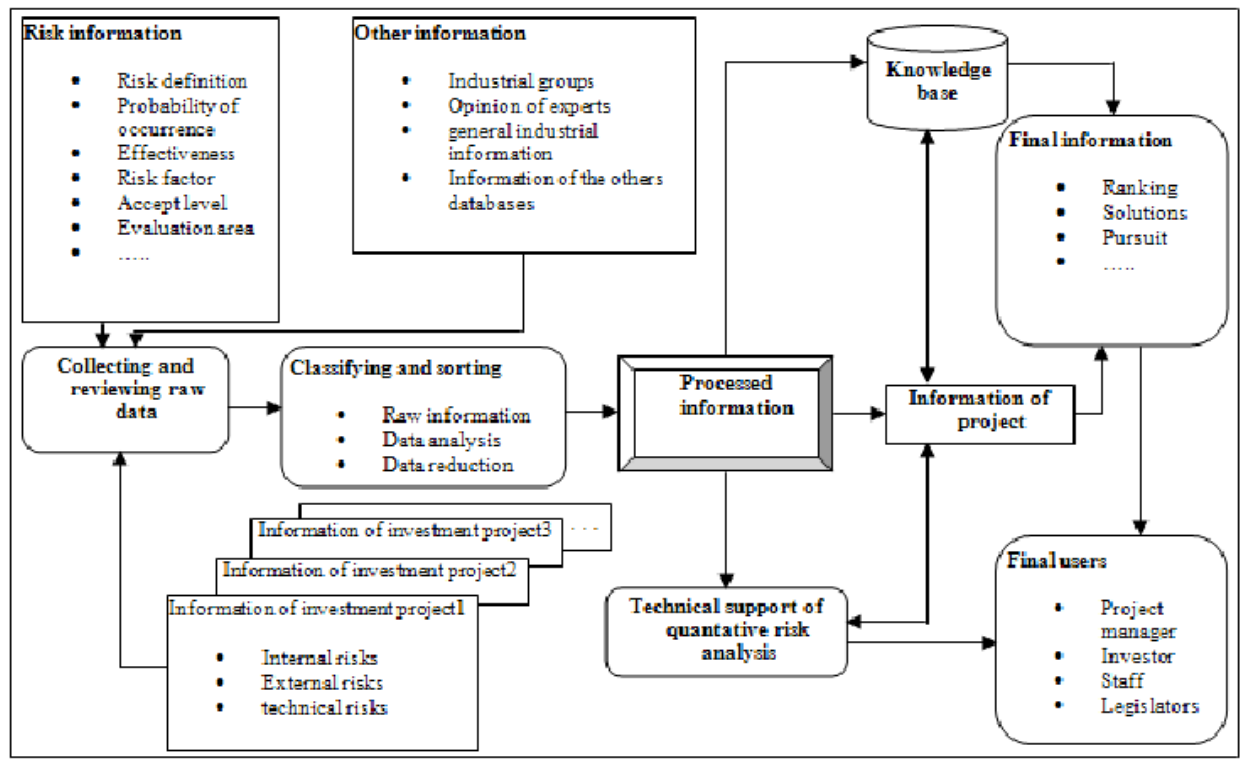

Fig 1: Structure of suggested database 


\section{Suggested Model Phases}

The suggested models have 8 separate phases. The order of these phases can be suggested and they are changeable in each project, and it is not necessary that all of the eight phases be in each project. To compare these phases with the standard of the risk management we are use the table 1.

Table1: The comparison of suggested model phases whit the structure of body of project management knowledge

\begin{tabular}{|c|c|}
\hline Suggested model phases & $\begin{array}{l}\text { The body of project } \\
\text { management knowledge }\end{array}$ \\
\hline- & $\begin{array}{c}\text { Programming risk } \\
\text { management process }\end{array}$ \\
\hline $\begin{array}{l}\text { - Structure phase } \\
\text { - Phase as determiner definition } \\
\text { methods of risks } \\
\text { - Determining risks phase } \\
\text { - Phase as determiner the accept levels } \\
\text { of risks }\end{array}$ & Identification risk process \\
\hline \multirow{2}{*}{$\begin{array}{l}\text { - Determination phase of suitable risk } \\
\text { evaluation methods } \\
\text { - Risk evaluation phase }\end{array}$} & $\begin{array}{l}\text { Quantitative risk analysis } \\
\text { process }\end{array}$ \\
\hline & $\begin{array}{l}\text { Qualitative risk analysis } \\
\text { process }\end{array}$ \\
\hline $\begin{array}{l}\text { - Phase as determiner of premiership of } \\
\text { answering to risks defined according } \\
\text { to Topsis technique } \\
\text { - Phase as determiner of effectiveness of } \\
\text { each risk on project and average risk } \\
\text { of evaluation area }\end{array}$ & $\begin{array}{l}\text { Process of answering to } \\
\text { risks }\end{array}$ \\
\hline- & $\begin{array}{l}\text { Risk pursuit and control } \\
\text { process }\end{array}$ \\
\hline
\end{tabular}

\section{5-1Structure phase}

In the structure phase the project is divided into specific areas. Each of these areas is called "evaluation area". For example, if the system is under studying one building project, these areas can be as building map, place of the building, earth preparation, financial sources, building materials and etc. 


\section{5-2 Phase as the determiner of the risk identification methods}

In this stage, between all the methods we try to find the best method according to the first identification. The most common methods which are used in different plans are: brainstorming, checklists, interview, studying the reports of the previous projects. Analysis failure, decision tree, Delphi technique, types of graphs (cause and effect diagram, system dynamics, effective factors diagram.) (Hatefi, 2008)

\section{5-3 Identification risk phase}

The aim of this phase is to identify the potential factors in creating a risk and all the events that are effective on the project. So we try to study each evaluation area.

\section{5-4 Phase as the determiner of the acceptable level of the risks}

In this phase the analyzer tries to determine the acceptable level of the risks. This can be possible by asking from the project managers. By determining the acceptable level of the risks, we can estimate the financial resources.

\section{5-5 Phase as determiner the best method for risk evaluation}

It is possible to determine the suitable evaluation method for each group of risks. Some of these methods that can be use dare: experts, simulation, scenario creating, using the analysis, financial analysis and etc. (Gharachorlu,2006)

\section{5-6 Risk evaluation phase}

Risk evaluation phase, is the risk estimating by using a specific method. To estimate the risk, many different evaluation methods can be used. Three indexes that in this model can be used for risk evaluation risk are: possibility of the event, effect and accepts level. One of the first ways of creating risk evaluation phase is to estimate each risk according to the probability of occurrence and its effect. We try to collect this information in database. 


\section{5-7 Determining the order of answering to the defined risks according to the Topsis technique}

In this phase we make decision about the order of answering to the defined risks according to their importance. Thus, those risks that need solution, transformation, division, reduction, improvement will be chosen. (Jaafari, 2001) So we face a multiple criteria decision making. Multiple criteria decision making issues are divided into parts: multiple objective decisions making and multiple criteria decision making. Multiple objective decisions making is used for planning but multiple criteria decision making is used for choosing the best option.( Asgharpour,1999)Thus, determining the order of answering the defined risk and choosing the most important risk are two kinds of multi criteria decision making. These issues are formulated according to the table2. $A_{i}$ shows choice $i_{\text {th }}$ and $X_{j}$ shows index $j_{\text {th }}$ and $r_{i j}$ shows index value $j_{\text {th }}$ for choiceith .

Table 2: Multi criteria decision making matrix

\begin{tabular}{|c|c|c|c|c|}
\hline Index & \multirow[t]{2}{*}{$X_{1}$} & \multirow[t]{2}{*}{$X_{2}$} & \multirow[t]{2}{*}{$\ldots$} & \multirow[t]{2}{*}{$X_{n}$} \\
\hline choice & & & & \\
\hline $\mathrm{A}_{1}$ & $r_{11}$ & $r_{12}$ & $\ldots$ & $r_{1 n}$ \\
\hline$A_{2}$ & $\mathrm{r}_{21}$ & $\mathrm{r}_{22}$ & $\ldots$ & $r_{2 n}$ \\
\hline · & - & . & . & $\cdot$ \\
\hline . & . & . & . & $\cdot$ \\
\hline . & . & . & . & $\cdot$ \\
\hline$A_{m}$ & $\mathrm{r}_{\mathrm{m} 1}$ & $r_{m 2}$ & $\ldots$ & $r_{m n}$ \\
\hline
\end{tabular}

On the other hand answering to the defined risk is determined according to the order of the risks. These orders play the role of option in the decision making matrix. Each risk depends to different factors, so related factors like risk effect are mentioned as decision making indexes. Therefore it is necessary to pay attention to the internal relations between indexes, and their effect on each other and their positive and negative aspects .According to the following definition the best option in multiple criteria decision making is $\mathrm{A}^{*}$ that provides the highest value(utility) of each characteristic. Means: 


$$
A^{*} \approx\left\{x_{1}^{*}, x_{2}^{*}, \ldots \ldots, x_{n}^{*}\right\} \stackrel{\text { when }}{\longrightarrow} x_{j}^{*}=\max _{i} U_{j}\left(r_{i j}\right) ; i=1,2, \ldots \ldots . m
$$

For mathematical operations, in matrix of multiple attribute decision making, it is necessary to change the qualities indexes to the quantities indexes. The changing will be done by using distance and two polar measures according to table 3 .

Table 3: Scale of bipolar distance measuring

\begin{tabular}{|c|c|c|c|c|c|c|}
\hline 0 & 1 & 3 & 5 & 7 & 9 & 10 \\
\hline- & $\begin{array}{c}\text { Very } \\
\text { little }\end{array}$ & Little & Average & High & $\begin{array}{c}\text { Very } \\
\text { much }\end{array}$ & - \\
\hline
\end{tabular}

If the matrixes are formed from the different types(for example one of them from cost, one of them from quality), dimensionless method must be used to make the indexes comparable for mathematical operation. After that we should put the risks in order according to the decision making method. Normalization, linear, average and fuzzy are some scale-building methods. In using dimensionless methods we should note that all the indexes of decision making matrixes should become dimensionless by one method. Also in using dimensionless methods all the indexes of making decision matrix should be a number between zero and one. (Asgharpour, 1999) In this paper we use normalization method because in this method it is not important that the indexes are positive or negative. According to equation 2, we divide each element of decision making matrix $\left(\mathrm{r}_{\mathrm{ij}}\right)$ to available norm of column $\mathrm{j}$ (per $\mathrm{x}_{\mathrm{i}}$ index)

$$
n_{i j}=\frac{r_{i j}}{\sqrt{\sum_{i=1}^{m} r_{i j}^{2}}}
$$

All the columns of decision making matrix has the same unit length, therefore the general comparison becomes easier. By mathematical operation in multi criteria decision making matrix we can calculate the weight of the indicators by using the Antropy Method. In this paper due to the computational ease of calculation of the weight indicators $\mathrm{w}_{\mathrm{i}}$ is calculated according to the equation3. 


$$
\begin{aligned}
& E_{j}=-\frac{1}{\ln m} \sum_{i=1}^{m}\left[p_{i j} \cdot \ln p_{i j}\right] ; \forall j \\
& d_{j}=1-E_{j} ; \forall j \quad p_{i j}=\frac{r_{i j}}{\sum_{i=1}^{m} r_{i j}} ; \forall i, j \\
& w_{j}=\frac{d_{j}}{\sum_{i=1}^{n} d_{j}} ; \forall j \quad w_{j}^{\prime}=\frac{\lambda_{j} \cdot w_{j}}{\sum_{i=1}^{n} \lambda_{j} \cdot w_{j}} ; \forall j
\end{aligned}
$$

The methods for solving multi criteria decision making problems consist of two groups: split methods of compensatory model and split methods of non-compensatory model. We cannot use the split methods of non-compensatory model to or 3) the risks of projects because in these methods cannot be any exchanges between the indicators. But in issue order of industrial project risk, the different indicators effect on each other. For example, it is possible that a risk because of because of high possibility of the occurrence not considered important, because it has a low effect.

A split method of compensatory model has three groups: scoring, compromise, coordinated. Each of these three groups has some methods. (Asgharpour, 1999 and Jayachitra,2010) We cannot use the methods of scoring subgroups to determine the order of answering the defined questions. For example we can use simple additive weighting method to find the best option based on the weight indicators. For another example the hierarchical additive weighting method can be used in those issues in which decision making indicators are shown in different levels. But, in risk order issue we cannot define the indicators in form of layers. Also interactive simple average weighting method can be used by considering the existence of a linear utility but unspecific. But in risk order issues of industrial plan the linear of the function cannot be determined.

From the compromise subgroups and coordinated subgroups only MRS cannot be used because this method can be used to solve the ranking of the industrial plan risk. Considering the dependence of indicators that form each plan, we cannot use them. Also, in this 
method the best option will be chosen. We chose Topsis because in using this algorithm the utility of each indicator must uniformly be reductional or increscent. The best value of each indicator shows the positive ideal and the worst value of each indicator shows the negative ideal. In this method, the selection option must have the shortest distance to the positive ideal and the longest distance to the negative ideal solution. Because of the simplicity of the algorithm, it is a suitable method. This algorithm has four stages: ( Asgharpour , 1999)

First step- forming weighty scale matrix $\left(Y_{m \times n}=N_{D} \cdot W_{m \times n}^{\prime}\right)$

$Y_{m \times n}:$ Weighty scale matrix

$N_{D}$ : Matrix, scaled by normal method

$W_{m \times n}^{\prime}:$ Matrix of weight indexes

Second step- determining ideal positive and negative option $\left(A^{*^{+}}\right.$ and $A^{*-}$ )

Third step-calculating distance of I option of weighty scale matrix from ideal positive and negative options $\left(d_{i}^{+}\right.$and $\left.d_{i}^{-}\right)$

Fourth step- calculating relative closeness of option to the ideal solution $\left(c_{i}\right)$

\section{8-5Phase as the determiner of the effect of each risk on the project and the average of the evaluation area of risk}

In this phase, the percent of effectiveness of each risk on industrial investment project and the average risk percent of each evaluation area can be gained according to the defined evaluation areas in the plan and the two indicators of the effectiveness of each risk. In this phase analyzer can answer to the questions such as: what kind of important risks are in each evaluation area. Does it need more evaluations? If yes, in which areas these evaluations should be used? Equations related to the expected impact of risks and the percent of risk effectiveness and the average of evaluation area risk is mentioned. 
Theexpectedriskimpact

= numericaldataofriskeffect

* probabilityofriskoccurrence

Percentofriskeffectonproject $=\frac{\text { expectedriskimpact }}{\text { thesumofexpectedrisksimpactonproject }} * 100$

Average risk of evaluation area (percent)=total percent of effective risks on evaluation area

\section{6-Database of risk registration system}

Database of risk registration system is used for documentation of the defined risks. This information facilitates the interlocution between the project managers. In this research, database of risk registration system is designed by Visual Basic and MS Access software. Also we studied on an industrial plan in a company which produces different types of refrigerator condenser or antithrush. As you see in the figure 2 according to the schedule first the number of industrial plan and title and description of the plan is obtained after that we want the user to determine the risk evaluation method such as event tree, simulation, scenario creating, opinion of experts and cause and effect diagram. At the end the user must enter the definition tool and usable evaluation to the specific places. If a suitable value of previous plans information is saved in knowledge base, the user will be able to use this information to define these risks.

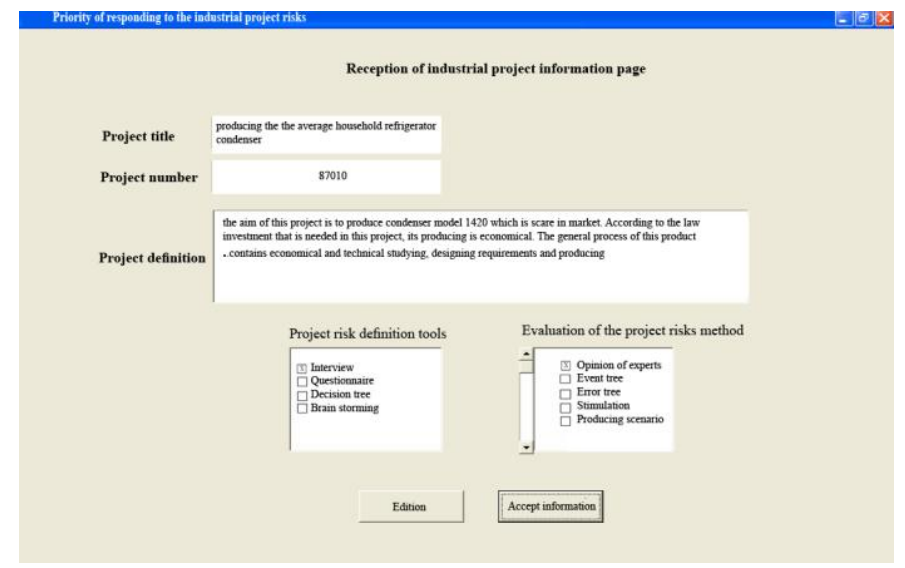

Fig 2: Reception of industrial project information page 
After entering and confirming the above information, the user will be sent to the risk information page. The user must open a new page for each defined risk and enter the information. This information consists of risk description, risk factor, evaluation area, the expected risks, risk possibility, risk effects and the acceptable level. In figure 3 a type of receipt page of risk information is shown. In the next stage, after the definition of the risk plans, according to the risk evaluation areas which are determined in structure phase, the defined risks will be put in order. The way of ordering is in such a way that from left to the right they define the number of the risks according to the risk type and evaluation area. For example, the risl1-A-M shows the risk number one, external which is un predictable and its evaluation area is material. The numbering of the defined risks in the project is determined by entering the risk information to risk register database system by automatically coding in VISUAL BASIC software.

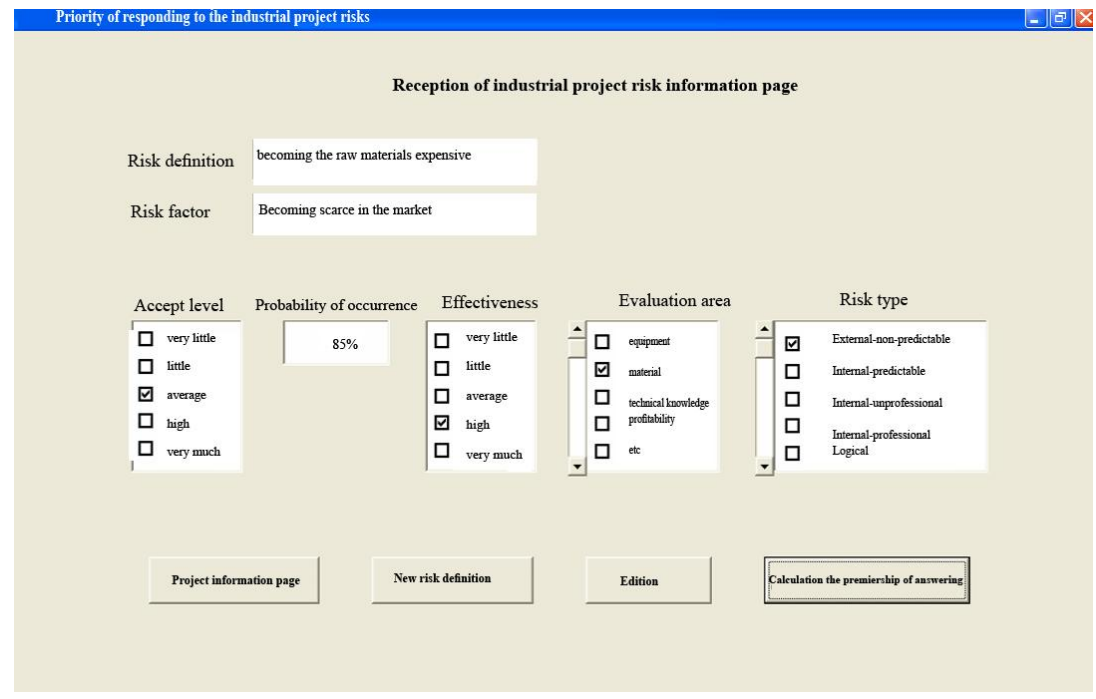

Fig 3: Reception of industrial project risk information page

This system is designed in such a way that its output can be easily modified and the previous calculation can be easily deleted and the new calculation can be easily entered. The reports can be used to draw the attentions to the risk condition reduction and adjustment program. The report page contains information such as risk grade 
also the risk number contains information such as risk type, evaluation, risk description, risk effect on evaluation area, number of active risks, risk possibility, expected risk effect. Table 4 contains the summary of output results related to risks of a new project or creating average refrigerator-freezer condenser which was provided as a report by designed database by using a central server the possibility of updating and saving the information is provided. The designed system is flexible and it gives this possibility to coordinate the structure and the content of the reports according to the special needs of each plan. And there is no limitation for user to select the definition and evaluation method.

Table 4: Page of reporting the suggested system

\begin{tabular}{|c|c|c|c|c|c|c|c|c|c|c|}
\hline \multirow{2}{*}{ 壬 } & \multirow{2}{*}{ 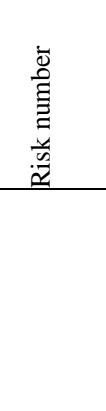 } & \multirow{2}{*}{ 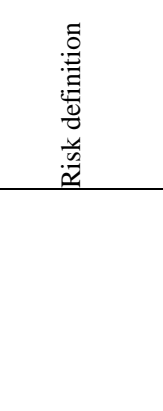 } & \multicolumn{5}{|c|}{$\begin{array}{l}\text { Effectiveness on evaluation } \\
\text { area(quantities) }\end{array}$} & \multirow{2}{*}{ 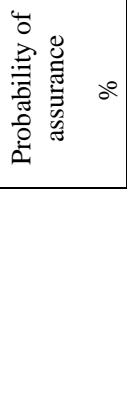 } & \multirow{2}{*}{ 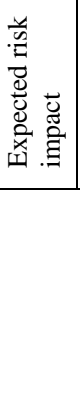 } & \multirow{2}{*}{ 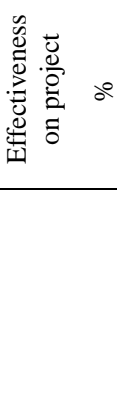 } \\
\hline & & & 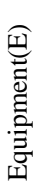 & 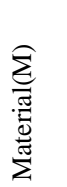 & 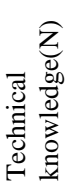 & 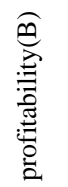 & $\widehat{\overbrace{}}$ & & & \\
\hline 1 & $8-B-N$ & $\begin{array}{l}\text { Lack of } \\
\text { specialist }\end{array}$ & & & 9 & & & 95 & $8 / 55$ & $11 / 2$ \\
\hline 2 & 1 -A-M & $\begin{array}{l}\text { Becoming } \\
\text { the raw } \\
\text { materials } \\
\text { more } \\
\text { expensive }\end{array}$ & & 7 & & & & 85 & $5 / 95$ & $7 / 8$ \\
\hline 3 & 1 -E-B & $\begin{array}{c}\text { Inefficient of } \\
\text { monetary } \\
\text { relations law }\end{array}$ & & & & 5 & & 90 & $4 / 5$ & $5 / 9$ \\
\hline$\vdots$ & $\vdots$ & $\vdots \vdots$ & $\vdots \vdots$ & $\vdots \vdots$ & $\vdots \vdots$ & $\vdots$ & $\vdots \vdots$ & $\vdots$ & $\vdots$ & $\vdots$ \\
\hline 22 & 3 -A-M & $\begin{array}{c}\text { Change of } \\
\text { material } \\
\text { properties }\end{array}$ & & 5 & & & & 20 & 1 & $1 / 3$ \\
\hline 23 & $2-C-B$ & $\begin{array}{l}\text { Products } \\
\text { returns }\end{array}$ & & & & 3 & & 20 & $0 / 6$ & $0 / 8$ \\
\hline 24 & 7 -D-B & $\begin{array}{l}\text { Delay in } \\
\text { activities }\end{array}$ & & & & 3 & & 20 & $0 / 6$ & $0 / 8$ \\
\hline & $\begin{array}{r}\text { mber of a } \\
\text { evaluati }\end{array}$ & $\begin{array}{l}\text { ive risks in } \\
\text { areas }\end{array}$ & 2 & 3 & 4 & 11 & 4 & & & \\
\hline & $\begin{array}{l}\text { rage risk } \\
\text { area(p }\end{array}$ & $\begin{array}{l}\text { evaluation } \\
\text { cent) }\end{array}$ & $3 / 6$ & $12 / 6$ & $29 / 3$ & $42 / 9$ & $11 / 5$ & & & \\
\hline
\end{tabular}




\section{Conclusion}

According to the information storage, and results of risk evaluation of each industrial plan in knowledge base related to the information bank, it is possible to use the information of previous plans in analyzing the risks of new project. Thus, after a short time it is possible to collect statistical data about different risks. Each organization can collect this database for itself and in higher levels the governmental organizations and investment service providers can benefit from having such a database exploit. For example, ministries can collect the information of different plans in form of this database and provides this information to the applicants. Also they can study different scenarios by using fuzzy logic. Another field that is suggested to be studied is about database. For example, suitable structure of creating data base and development of software and hardware systems must be studied.

\section{Reference}

Aaby, A. (2006). An overview of project and risk management. Washington: Computer Science Department, Walla Walla University.

Aladpoosh, H. (2002). Project management, Tehran,Iran: HamiPress.

Javad, A. M. (1999). Multiple criteria decision making. Tehran University Press.

Chapman, C. B., \& Ward, S. C. (2008). Project risk management: Processes, techniques and insights, ( $2^{\text {nd }}$ ed.). Chichester, UK .John Wiley.

Eloranta, A. J. (2007). Risk management in venturing software companies, Helsinki, Finland, Helsinki University of Technology, Seminar in Business Strategy and International Business.

Gharachorlu, N. (2006). Risk analysis and risk management. Tehran, Iran: Oloom \& Fonoon Press.

Hatefi, M. A. (2008). Development of the projects risk integrated model. A thesis submitted to the faculty of industrial engineering of the IUST in practical fulfilment of the requirements for the degree of Ph.D., Iran University of Science and Technology (IUST)

Hillson, D. (2002). Extending the risk process to manage opportunities. International Journal of Project Management, 20, 235240 . 
Jaafari, A. (2001). Management of risks, uncertainties and opportunities on projects: Time for a fundamental shift, International Journal of Project Management, 19, 89- 101.

Kerzner, H. (2001). Project management: A systems approach to planning, scheduling, and controlling, (7th ed.). John Wiley \& Sons.

Kliem, R., \& Ludin, I. (1995.). Making reuse a reality. Software Development, 3(12) 63-69.

Mohammadi, A. (2006). A managing and analysis model for construction projects risk in petrochemical industries. A dissertation submitted for the degree of $\mathrm{PhD}$ in Socio-Economic Systems Engineering, KhajeNasir University, Tehran, Iran.

National Research Council (NRC), (1983), Risk assessment in the federal government: Managing the process, Washington, DC: National Academy of Sciences.

Neda, M. H. (2006), Crisis management and its effect on the urban gas facilities and its solution. A dissertation submitted for the degree of PhD in Economic Systems Engineering, Tehran, Iran. Iran University of Science and Technology.

Jayachitra, R., \& Prasad, P. S. S. (2010). Design and selection of facility layout using simulation and design of experiments, Indian Journal of Science and Technology, 3(4), 37-447

Robert, I. M., \& Bob, A. H. (1963). Risk management: Concepts and applications. USA: McGraw-Hill Inc.

Santos, S. D. F. R., \& Cabral, S. (2005). FMEA and PMBOK applied to project risk management, International Conference on Management of Technology, Vienna, Italy.

Vose, D. (2000). Risk analysis: A quantitative guide (2nd ed.). John Wiley \& Sons.

Vaughan, E. J. (1997). Risk management, USA: John Wiley \& Sons, Inc.

Yang, J., \& W. Qiu. (2005). A measure of risk and decision making model based on expected utility and entropy, European Journal of Operational Research, 164, 792-799.

Zhuan, N. (2008), Risk management in information technology system, A dissertation Submitted for the degree of $\mathrm{PhD}$ in Economic Systems Engineering, Iran University of Science and Technology, Tehran, Iran. 